\title{
Estudo de toxicidade retiniana após injeções intravítreas seriadas de infliximabe em olhos de coelhos
}

\section{A safety study of retinal toxicity after serial intravitreal injections of infliximab in rabbits eyes}

Alan Ricardo Rassi ${ }^{1}$, Moacyr Pezati Rigueiro², David Leonardo Cruvinel Isaac ${ }^{1}$, Letícia Dourado², Murilo Batista Abud ${ }^{3}$, Éricka Campos Freitas ${ }^{4}$, luciana Barbosa Carneiro ${ }^{5}$, Marcos Pereira de Ávila ${ }^{6}$

\section{RESUMO}

Objetivo: Determinar os níveis de toxicidade de duas e três aplicações intravítreas de infliximabe na retina de coelhos albinos, por meio de exames clínicos oftalmológicos, eletrorretinográficos e histológicos.

Métodos: Foram utilizados doze coelhos albinos divididos em dois grupos. No primeiro grupo de 10 coelhos, cada olho recebeu duas ( $n=10$ olhos) ou três injeções ( $\mathrm{n=10}$ olhos) intravítreas de $2 \mathrm{mg}$ de infliximabe dissolvidos em 0,06 $\mathrm{ml}$ de solução salina, em intervalos mensais. Um segundo grupo de dois coelhos, que serviu como grupo controle ( $n=4$ olhos), foram submetidos a duas e três aplicações intravítreas de BSS. Noventa dias após, os coelhos foram novamente submetidos a exame oftalmológico (biomicroscopia, oftalmoscopia e tonometria), eletrorretinográfico e, após enucleados, a exame histológico.

Resultados: O exame biomicroscópico e oftalmoscópico não revelou anormalidades retinianas nos olhos injetados com infliximabe e no grupo controle. Alteração histológica notada foi a presença de raros linfócitos e eosinófilos no vítreo posterior em quatro e em seis olhos submetidos a duas e três aplicações de infliximabe sem significado clínico. A única alteração clinicamente significante foi uma reação inflamatória severa com presença de exsudatos vítreos na interface vítreo retiniana e discreto edema de células ganglionares nos dois olhos de um único coelho, sem alterações no vítreo posterior. Os exames eletrorretinográficos mostraram amplitudes em média $12-13 \%$ menores daquelas obtidas antes do tratamento, contudo não houve nenhuma diferença estatisticamente significante quando comparamos as amplitudes e a latencia entre os achados electrorretinográficos pré e pós-tratamento.

Conclusão: Duas e três aplicações intravítreas de infliximabe em olhos de coelhos em intervalos mensais, na dosagem de $2 \mathrm{mg}$, não provocam alterações significantes após um seguimento de noventa dias, quer no exame histológico, na eletrorretinografia e na avaliação clínica oftalmológica. Conclui-se que doses seriadas de infliximabe por via intravítrea é um procedimento seguro. Estudos clínicos em humanos devem ser realizados para melhor avaliação da segurança do seu uso no tratamento de determinadas doenças que acometem a retina e a coroide.

Descritores: Fator de necrose tumoral alfa; Injeções intravenosas; Retina; Doenças retinianas/quimioterapia; Doenças da coróide/quimioterapia; Degeneração macular; Anticorpos monoclonais/administração \& dosagem; Eletrorretinografia; Animais; Coelhos

\begin{abstract}
Purpose: To determine retinal and choroid toxicity levels of two and three infliximab intravitreous injections in albino rabbits by means of electroretinographic, histologica and ophthalmological clinical tests.

Methods: 12 albino rabbits were used in the study. Each eye was given two ( $n=10$ eyes) or three ( $n=10$ eyes) serial intravitreous $2 \mathrm{mg}$ infliximab injections dissolved in $0.06 \mathrm{ml}$ of saline, at monthly intervals. A separate group of rabbits ( $n=4$ eyes) served as a control group. Ninety days after the study had begun, the rabbits underwent clinical and electroretinographic tests, and after being enucleated, the eyes were examined for histological changes.

Results: Slit-lamp biomicroscopy and fundoscopic examination did not reveal any significant retinal abnormalities in the eyes injected with infliximab and control eyes or in pre- and post-treated eyes. The histological change that was noted was the presence of rarelymphocytes and eosinophils in the posteriorvitreous of some of the rabbits subjected to two or three injections, but it was not considered clinically significant. A severe inflammatory reaction with vitreous exudates and ganglion cell edema in a single rabbit was clinically significant. The electroretinographic tests showed amplitudes that were on the average 12-13\% smaller than those obtained before the treatment, however, there were no statistically significant differences when comparing the amplitude or the implicit time between pre-and post-treatment electroretinographic findings.

Conclusion: Two and three intravitreous $2 \mathrm{mg}$ infliximab injections in rabbits at monthly intervals did not cause any changes after a 90-day follow-up, according to histological and electroretinographic tests and after clinical evaluation. Differently from prior studies that have investigated potential retinotoxicity effects after single administrations, this study investigated the possibility of retinotoxicity after multiple injections. Clinical studies in humans should be conducted to better evaluate the safety of this drug in the treatment of certain diseases affecting the retina and the choroid.
\end{abstract}

Keywords: Tumor necrosis factor-alpha; Injections, intravenous; Retina; Retinal diseases/ drug therapy: Choroid diseases/drug therapy: Macular degeneration: Antibodies, monoclonal/administration \& dosage; Electroretinography; Animals; Rabbits
Submitted for publication: February 8, 2011

Accepted for publication: August 30, 2011

Study carried out at the Centro de Referência em Oftalmologia da Faculdade de Medicina da Universidade Federal de Goiás (CEROF/UFG).

${ }^{1}$ Physician, Ophthalmology Department, Centro de Referência em Oftalmologia, Universidade Federal de Goiás - UFG - Goiânia (GO), Brazil.

Physician, Pathology Department, Universidade Federal de São Paulo - UNIFESP - São Paulo (SP), Brazil.

${ }^{3}$ Physician, Setor de Retina e Vítreo, Centro de Referência em Oftalmologia, Universidade Federal de Goiás - UFG - Goiânia (GO), Brazil.

Physician, Setor de Eletrofisiologia, Centro de Referência em Oftalmologia, Universidade Federal de Goiás - UFG - Goiânia (GO), Brazil.

${ }^{5}$ Assistant, Setor de Eletrofisiologia, Centro de Referência em Oftalmologia, Universidade Federal de Goiás - UFG - Goiânia (GO), Brazil.

${ }^{6}$ Professor, Ophthalmology Department, Centro de Referência em Oftalmologia, Universidade Federal de Goiás - UFG - Goiânia (GO), Brazil.
Funding: No specific financial support was available for this study.

Disclosure of potential conflicts of interest: A.R.Rassi, None; M.P.Rigueiro, None; D.L.C.Isaac, None; L.Dourado, None; M.B.Abud, None; E.C.Freitas, None; L.B. Carneiro, None; M.P.Ávila, None Correspondence address: Alan Ricardo Rassi. Rua T-48, 100 - Ap. 1101 - Setor Oeste - Goiânia (GO) - 74140-130 - Brazil -E-mail: alanrassi@ipvisao.com.br 


\section{INTRODUÇÃO}

Fator de necrose tumoral alfa (TNF) é uma citocina sintetizada pelos macrófagos e linfócitos $T$, em resposta a infecções e injúrias imunológicas. Liga-se a receptores da superfície das células, exacerbando a inflamação e induzindo a liberação de outras citocinas pró-inflamatórias sendo neutralizadas pela ação de citocinas antiinflamatórias ${ }^{(1)}$. Estudo identificou importante papel do TNF na patogênese da retinopatia diabética, degeneração macular relacionada à idade (DMRI) e uveíte, permitindo assim prever que a utilização de drogas antiTNF poderiam apresentar benefícios no seu tratamento ${ }^{(2)}$. Experimentos realizados em coelhos mostraram que TNF, pelas suas propriedades infamatórias, é capaz de induzir a liberação do fator de crescimento vascular endotelial (VEGF). A presença conjunta do TNF e VEGF foi determinada no endotélio e paredes vasculares do tecido fibrovascular e vítreo de olhos com retinopatia diabética proliferativa ${ }^{(3,4)}$. Em modelo animal tem sido demonstrada a regressão de neovascularização, após tratamento com drogas antiTNF(5). Estudos em animais e humanos sugerem que TNF tem importante papel no desencadeamento e manutenção da uveíte experimental|(6-8). O papel pró-inflamatório do TNF na uveíte é sustentado pela observação de que a injeção intraocultar em coelhos induz a formação de uveíte ${ }^{(9,10)}$. Em humanos portadores de uveíte, elevados níveis de TNF foram demonstrados no humor aquoso coletado no intraoperatório(11). Aumento dos níveis de TNF foi encontrado em vasculites retinianas (doença de Behçet) e oftalmia simpática ${ }^{(12)}$. A presença de inflamação tem sido demonstrada em membrana neovascular removida cirurgicamente em pacientes com degeneração macular relacionada à idade $\left.(\mathrm{DMRI})\right|^{(13-15)} \mathrm{e}$ TNF tem sido encontrado em pacientes com degeneração DMRI ${ }^{(16)}$.

Infliximabe é um anticorpo monoclonal quimérico humano murino que se liga ao TNF, levando à perda de sua bioatividade. É administrado por via endovenosa e utilizado no tratamento da artrite reumatoide ${ }^{(17)}$, doença de $\mathrm{Crohn}^{(18)}$, doença de Behçet ${ }^{(19)}$ e espondilite anquilosante ${ }^{(20)}$. Porém, efeitos adversos aparecem com frequência, como o desenvolvimento de doenças infecciosas, malignas, reações durante infusão endovenosa e desenvolvimento de autoimunidade. Pacientes podem desenvolver anticorpos humanos antiquiméricos (HACA) e antimurinos com o uso de infliximabe ${ }^{(21)}$. Pacientes portadores de uveíte e doença de Behçet foram tratados com infliximabe, por via endovenosa, e remissão do processo inflamatório ocular tornou-se evidente em 24 horas, e sua completa supressão, após sete dias, em todos os pacientes ${ }^{(22)}$. Foi notado ainda que, em dois pacientes com artrite reumatoide e DMRI, a infusão endovenosa de infliximabe causou regressão da membrana neovascular ${ }^{(23)}$. Pacientes com diabetes tipo 2 portadores de edema macular apresentaram melhora acentuada após uso de infliximabe por via endovenosa ${ }^{(24)}$.

Com a administração intravítrea de infliximabe, obtêm-se concentrações terapêuticas com mínima absorção sistêmica, diminuindo os seus efeitos colaterais.

\section{MÉTODOS}

Foram estudados doze coelhos albinos, da raça New Zealand, com protocolo aprovado pelo Comitê de Ética em Pesquisas Humanas e Animais da Universidade Federal de Goiás. Eles foram tratados de acordo com normas da Association for Research in Vision and Ophthalmology (ARVO).

Os coelhos foram mantidos em gaiolas individuais, em ambiente climatizado, e supervisionados por veterinário. Foram divididos em um grupo com dez coelhos e o segundo grupo com dois coelhos, que serviram como controle. Todos os olhos foram submetidos a exames clínicos oftalmológicos (biomicroscopia, oftalmoscopia binocular, tonometria) e eletrorretinográficos. Dois olhos do grupo controle foram submetidos a duas aplicações de solução salina balanceada (BSS), e os outros dois olhos, a três aplicações de BSS.
No outro grupo, dez olhos receberam duas aplicações de infliximabe e dez olhos, três aplicações de infliximabe. O exame clínico oftalmológico completo foi realizado no pré-operatório, após todas as injeções intravítreas e trinta dias após a última aplicação. Os exames eletrorretinográficos, antes da primeira aplicação, e 30 dias após a última aplicação. Infliximabe (Remicade 100 mg ${ }^{\mathrm{TM}}$ ) foi reconstituída com $3 \mathrm{ml}$ de solução salina, tendo sido injetado em cada olho $0,06 \mathrm{ml}$ da solução (2 mg de infliximabe). Os animais foram anestesiados com uma associação de cloridrato de xilazina e cetamina por via intramuscular. As injeções intravítreas foram realizadas a $2 \mathrm{~mm}$ do limbo supero-temporal. Os olhos foram dilatados com fenilefrina e cicloplégico. Foi utilizado moxifloxacino colírio no pré e pós-operatório. Os coelhos foram submetidos mensalmente a injeções intravítreas (dias 1, 30 e 60). Noventa dias após a primeira aplicação, foi realizado novo exame oftalmológico e eletrorretinográfico. A eutanásia foi feita logo após, administrando cloreto de potássio a 10\%. Os olhos foram enucleados e fixados em solução de formol a 10\%, etanol a 70\%, por mais de 24 horas e submetidos a cortes com navalha, retirando-se fatia de aproximadamente $3 \mathrm{~mm}$ de espessura, desde a córnea até o nervo óptico. Essas fatias foram incluídas em parafina e realizados cortes em micrótomos na espessura de 5 micrômetros. Os cortes foram corados pela técnica hematoxilina-eosina. Exames foram realizados em microscópio óptico Olympus, e as lâminas, fotografadas com câmera digital.

Eletrorretinografia (Figura 1) foi efetuada após dilatação e adaptação ao escuro por dez minutos com luz de fundo da cúpula contraste. O exame foi gravado no aparelho alemão Roland Consult, em mesa adaptada para exames de animais. Foi utilizado eletrodo corneano unipolar para animais, diâmetro de $11 \mathrm{~mm}$. O eletrodo negativo foi localizado na língua, e o terra, no pavilhão auricular. Foi realizada fase fotópica para avaliação do sistema de cones, em sala escura, após adaptação ao claro, com luz do fundo da cúpula, durante dez minutos. Todos os estímulos foram repetidos três vezes com flashes fotópicos. O sinal biológico foi amplificado e analisadas as amplitudes pico a pico das ondas e tempo de latência. A diminuição da amplitude maior que 30\% foi considerada anormal.

\section{RESULTADOS}

\section{Resultados dos eXames Clínicos oftalmológicos}

Os olhos não apresentaram opacificações corneanas e aumento da pressão intraocular. Notou-se presença de pequena opacificação de cristalino periférico em dois olhos, provocadas pelas injeções intravítreas. Exame com oftalmoscópio binocular indireto não constatou descolamento de retina, alterações na retina e no nervo óptico ou presença de opacificações e sinais inflamatórios no vítreo.

\section{Resultados dos exames eletroRRETINOGRÁficos}

Nos exames das ondas a e b não foram encontradas diferenças significativas tanto na morfologia quanto nas amplitudes dessas ondas. O eletrorretinograma revelou presença de ondas detectáveis durante todo o exame em todos os grupos, com resposta normal, tanto em relação à amplitude quanto ao tempo implícito das ondas a e b. Essas respostas ocorreram no exame inicial e noventa dias após a injeção de infliximabe e BSS em todos os grupos. Em nenhum momento, houve redução significativa ou ausência de resposta ao eletrorretinograma pelo estímulo utilizado. A medida das ondas a e b não revelaram alterações morfológicas e funcionais em nenhum dos grupos.

\section{Resultados dos exames histológicos}

Não foram encontrados descolamento e edema de retina e nem percebidas alterações histológicas na retina sensorial, epitélio pigmentar e coroide de todos os olhos estudados. Não se constataram sinais de atrofia e edema tanto nas células como na espessura das camadas retinianas e da coroide (Figura 2). Uma pequena alteração encontrada em quatro e seis olhos submetidos a duas e três aplicações de infliximabe respectivamente foi a presença, no vítreo, de 


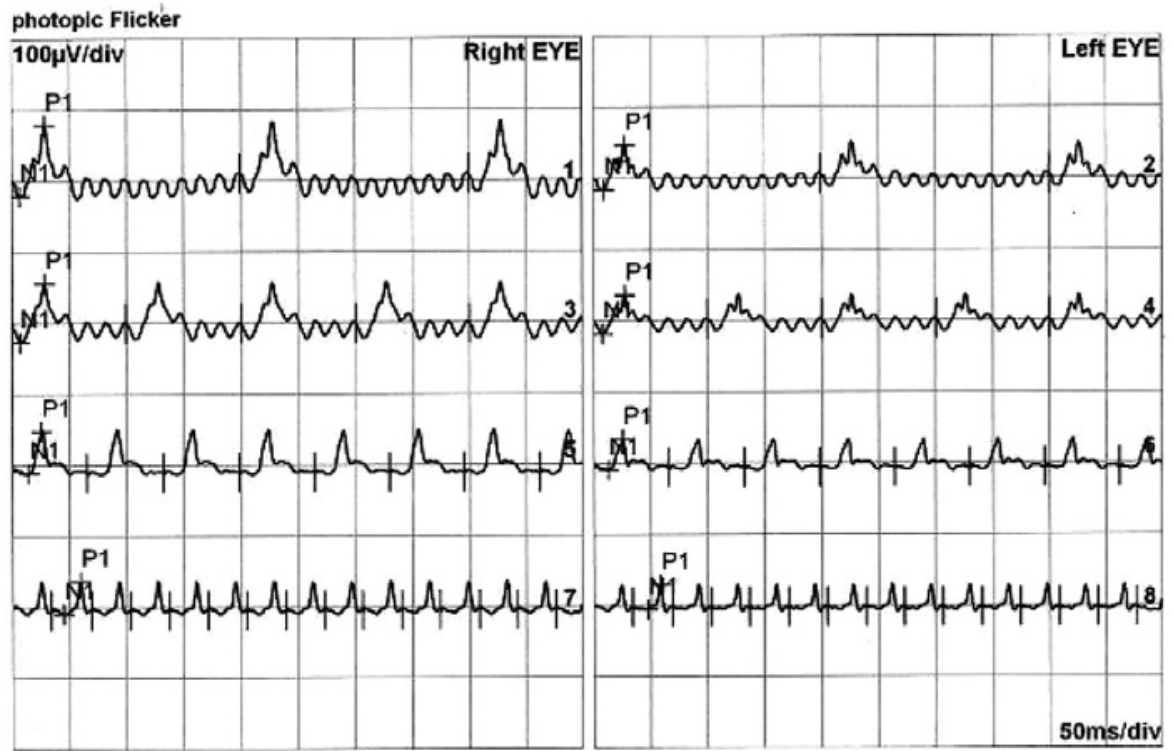

Figura 1. Eletrorretinografia de dois olhos de um coelho.

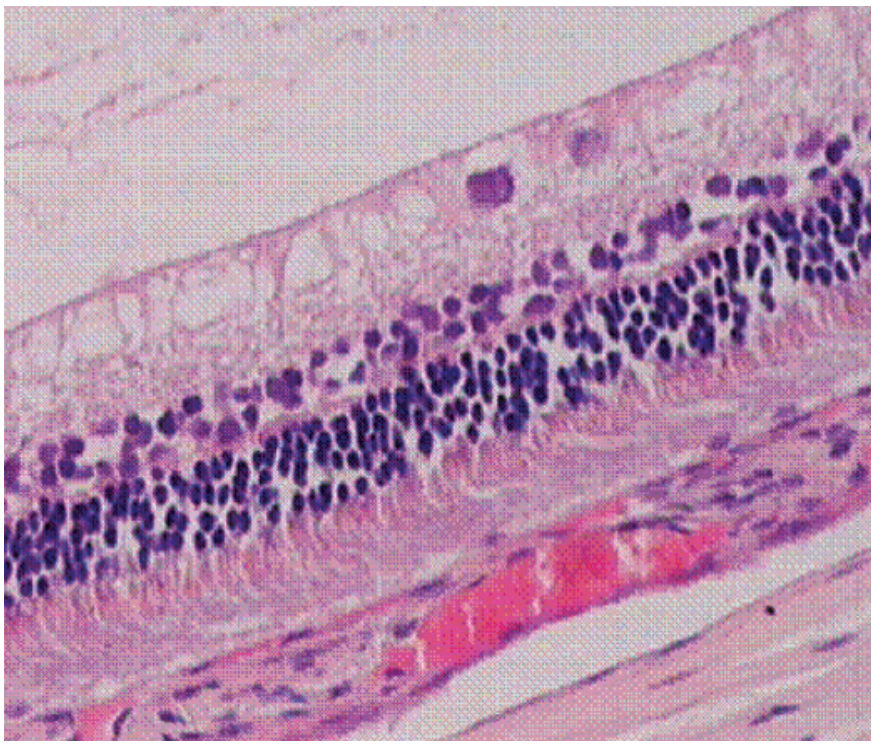

Figura 2. Exame histológico de retina sem alterações.

raros linfócitos e eosinófilos, sem comprometimento retiniano e sem significado clínico (Figura 3). Uma única alteração clinicamente significativa encontrada nos dois olhos de um único coelho que foi submetido a duas e três aplicações de infliximabe, foi uma reação infamatória com presença de fibrina no vítreo posterior, sem alterações na camada de células ganglionares e no restante do vítreo (Figura 4).

\section{AnÁlise estatística das avaliações eletrorretinográficas}

Para avaliar as diferenças entre as duas visitas, primeiro, realizou-se o teste F de homogeneidade de variância. Quando não foi encontrada diferença de variâncias, utilizou-se o teste $T$ pareado para efetuar as comparações entre as visitas. Após análise pelos testes estatísticos, observou-se um único caso em que houve diferença de variâncias ocorrido na comparação entre a primeira e a segunda visita para P1 (20 ms) de olho direito e, nesse caso, foi utilizado alternativamente o teste não paramétrico de postos com sinais de
Wilcoxon. Em todas as comparações efetuadas não foram encontradas diferenças estatisticamente significantes entre a primeira e a segunda visita.

\section{AnÁlise estatística das aValiações histológicas}

Como só houve alterações nos olhos de um único coelho, o teste exato de Fisher mostrou um valor de $p$ de 1.0, ou seja, não houve diferença estatística entre os olhos submetidos à injeção de BSS e duas e três aplicações de infliximabe. Como só houve alteração nos dois olhos de um único coelho, ela não é estatisticamente significativa.

\section{DISCUSSÃO}

A administração intravítrea de drogas tem sido utilizada com constante frequência para o tratamento de diversas doenças que acometem a retina, a coroide e o vítreo. Em geral, essa via é segura e com menor incidência de efeitos colaterais sistêmicos quando comparada à oral ou à endovenosa, pois a administração direta da droga na cavidade vítrea proporciona maior concentração terapêutica e menor biodisponibilidade sistêmica.

Os primeiros trabalhos com infliximabe intravítreo foram feitos em coelhos albinos ${ }^{(25)}$. Diferentes doses foram injetadas no vítreo, e estudos clínicos, eletrorretinográficos e histológicos indicaram que dosagem de 1,7 mg provou ser segura para a retina. Doses acima de 3,3 mg causaram significante edema do nervo óptico. Em outro estudo(26), doses crescentes de injeções intravítreas de infliximabe mostrou, após 45 dias, alterações nas células de retina com doses superiores a $5 \mathrm{mg}$. Concluiu-se que $2 \mathrm{mg}$ é uma dose segura para a retina de coelhos. Estudos realizados em coelhos, com a indução de uveíte com uso de endotoxina da salmonela ${ }^{(27)}$ demonstraram que o uso de infliximabe intravítreo, além de não provocar toxicidade, suprimia a inflamação provocada pela endotoxina.

A primeira experiência com o uso de infliximabe por via intravítrea em pacientes com DMRI foi relatada em um artigo ${ }^{(28)} \mathrm{em}$ que os autores apresentaram um estudo realizado em três pacientes que não obtiveram bons resultados com ranibizumabe mas quando submetidos a duas aplicações intravítreas de infliximabe, houve melhoria na acuidade visual e diminuição da espessura foveolar, com utilização de uma dosagem de $2 \mathrm{mg}$, sem efeitos colaterais. Um segundo estudo em humanos ${ }^{(29)}$ utilizando dosagem bem menor $(0,5 \mathrm{mg})$ em dois pacientes com retinopatia diabética e edema 


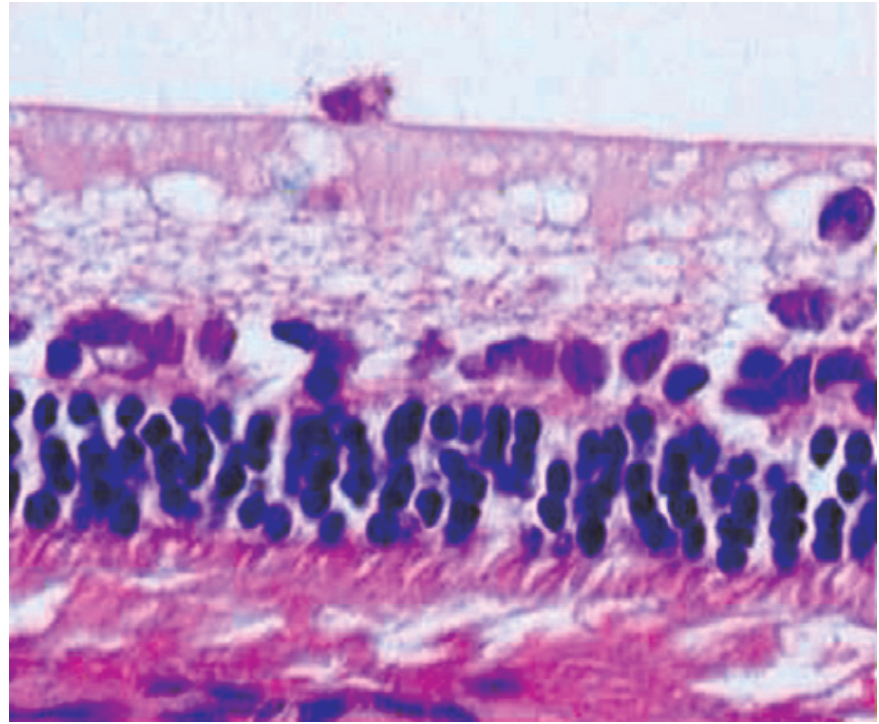

Figura 3. Exame histológico mostrando presença de linfócito.

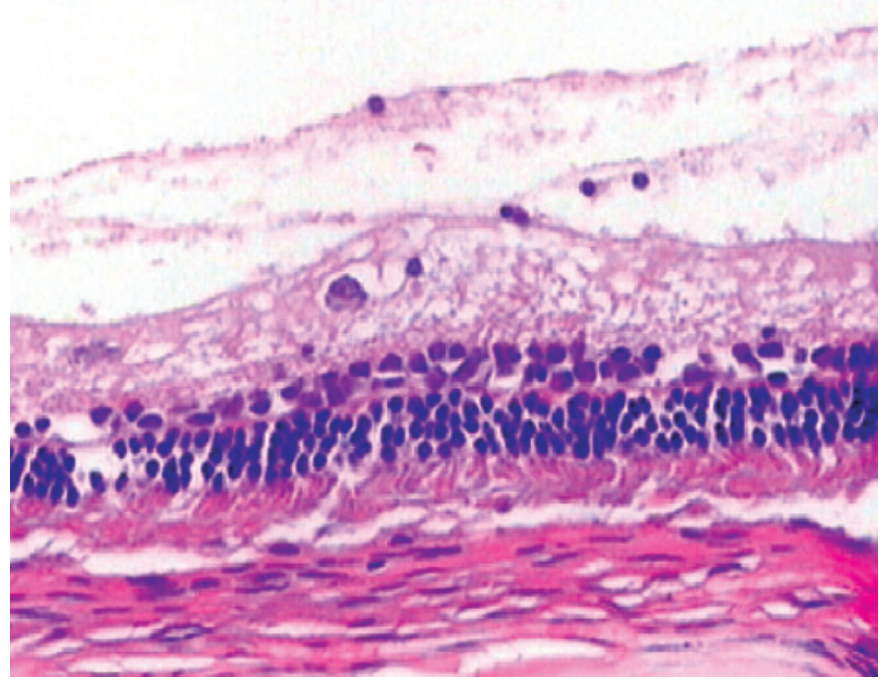

Figura 4. Presença de reação inflamatória na interface vitreorretiniana.

macular, e dois com DMRI e membrana neovascular, constatou-se piora da acuidade visual e do edema macular, com alterações no eletrorretinograma.

Entretanto, duas diferenças devem ser ressaltadas entre os dois estudos: no primeiro ${ }^{(29)}$, os pacientes tinham recebido somente uma dose de ranibizumabe e, no outro ${ }^{(30)}$, várias doses de medicamentos antiangiogênicos já haviam sido utilizadas sem sucesso, e dois pacientes já tinham tido reações inflamatórias após o uso de triancinolona e bevacizumabe. Outra diferença significativa entre os dois estudos consistiu na dosagem mais alta $(2 \mathrm{mg} \times 0,5 \mathrm{mg}$ ) usada no primeiro trabalho ${ }^{(29)}$. Sabe-se que quando infliximabe é utilizado por via sistêmica, paradoxalmente, dosagens mais altas têm menor possibilidade de provocar o desenvolvimento de anticorpos humanos antiquiméricos (HACAs) ${ }^{(21)}$. Trabalho publicado recentemente utilizando $1,5 \mathrm{mg}$ de infliximbe intravítreo em pacientes portadores de uveite crônica não infeciosa não mostrou reação inflamatória em nenhum dos olhos examinados, com melhora tanto da acuidade visual como do edema macular ${ }^{(30)}$.
Um protocolo clínico, financiado por National Eye Institute, está recrutando participantes para determinar se infliximabe ou outras drogas imunossupressoras podem ser usadas no tratamento de membrana neovascular em DMRI.

Os estudos do uso de infliximabe intravítreo em coelhos, até o presente momento, utilizaram sempre uma única aplicação com resultados convincentes da segurança dessa droga ${ }^{(25,26)}$. O presente estudo avaliou os efeitos eletrofisiológicos e histológicos da retina de coelhos após duas e três aplicações de infliximabe, em intervalos mensais. O volume e a dosagem utilizados $(0,06 \mathrm{ml} / 2 \mathrm{mg})$ foram bem tolerado pelos olhos dos coelhos, não causando aumento da pressão intraocular. A única alteração histológica notada foi a presença no vítreo de raros linfócitos e eosinófilos, sem significado clínico. Foram encontradas tanto em olhos submetidos a duas como a três aplicações de infliximabe.

Esses achados não apresentaram alterações histológicas na retina sensorial, epitélio pigmentar e coroide, seja na morfologia das células ou na espessura das camadas. Provavelmente, trata-se somente de uma discreta reação inflamatória vítrea ou micro-hemorragias causada pela injeção, não tendo significado clínico e não representando reação tóxica ao medicamento.

Em dois olhos de um mesmo coelho, submetido a duas e três aplicações de infliximabe notou-se reação inflamatória bem mais acentuada, com aparecimento de material fibrinoide no vítreo posterior, sem comprometimento da retina sensorial, que pode ou não estar relacionado ao uso do medicamento, mas sem valor estatístico. Possíveis razões para a resposta inflamatória à injeção intravítrea de infliximabe incluem reações ao anticorpo monoclonal, a proteínas desconhecidas ou a contaminações presentes com o uso da droga.

O infliximabe é um anticorpo monoclonal 35\% murino e 65\% humano, diferente do bevacizumabe e ranibizumabe, que são totalmente humanos. Por causa de sua composição, ele pode incitar uma reação imunogênica e levar à produção de anticorpos, sobretudo se a dosagem inicial for baixa ou não sustentada. É também possível que impurezas proteicas ou contaminações desconhecidas tenham sido responsáveis pela reação inflamatória. Deve-se ter em mente também que infliximabe, por ser um anticorpo com proteínas humanas e murinas, pode levar a reações inflamatórias com menor frequência em humanos do que em coelhos, já que os dois anticorpos são estranhos a essa espécie animal.

Como não houve alterações na morfologia das ondas a e b antes e após as injeções, a função eletrorretinográfica da retina não foi alterada com o uso da droga. Os estudos de todas as lâminas obtidas dos olhos dos coelhos não revelaram a presença de alterações nas diversas camadas da retina, o que corrobora a não toxidade do uso intraocular de duas e três aplicações de infliximabe.

\section{CONCLUSÃO}

Após avaliação dos exames clínico-oftalmológicos, anatomopatológicos e eletrorretinográficos pode-se afirmar que duas e três injeções intravítreas de infliximabe na dosagem de 2 mg, em intervalos mensais, não provocam alterações tóxicas nas retinas de coeIhos. A única alteração encontrada foi a presença de raros linfócitos e eosinófilos clinicamente insignificantes no vítreo, decorrentes ou de uma pequena reação inflamatória ou, mais provavelmente a micro-hemorragias em reabsorção causadas pelo trauma cirúrgico das injeções intravítreas. Não houve comprometimento na estrutura histológica das camadas sensoriais retiniana e do nervo óptico. Em um único coelho submetido a duas e três aplicações de infliximabe, foi encontrada uma reação fibrinoide, sem comprometimento das camadas da retina sensorial e sem valor estatístico significante. Essa alteração só foi detectada ao exame anatomopatológico, não tendo sido visualizada ao exame oftalmoscópico.

Conclui-se que duas ou três injeções de infliximabe intravítreo na dosagem de 2 mg mostram-se seguras em coelhos, por não 
produzirem alterações tóxicas no seu tecido retiniano e coroide. Estudos clínicos devem ser realizados para melhor avaliação da segurança do uso dessa substância, por via intravítrea, em seres humanos.

\section{REFERÊNCIAS}

1. Locksley RM, Killeen N, Leonardo MJ. The TNF and TNF receptor superfamilies: integrating mammalian biology. Cell. 2001;104(4):487-501.

2. Joussen AM, Poulaki V, Le ML, Koizumi K, Janicki H, Schraemeyer U, et al. A central role for inflammation in the pathogenesis of diabetic retinopathy. FASEB J. 2004;18(12):1450-2.

3. Limb GA, Chignell AH, Green W, LeRoy F, Dumonde DC. Distribution of TNF alpha and its reactive vascular adhesion molecules in fibrovascular membranes of proliferative diabetic retinopathy. Br J Ophthalmol. 1996:80(2):168-73.

4. Armstrong D, Augustin AJ, Spengler R, Al-Jada A, Nikola T, Grus F, et al. Detection of vascular endothelial growth factor and tumor necrosis factor alpha in epiretinal membranes of proliferative diabetic retinopathy, proliferative vitreoretinopathy and macular pucker. Ophthalmologica. 1998;212(6):410-4.

5. Shi X, Semkova I, Müther PS, Dell S, Kociok N, Joussen AM. Inhibition of TNF-alpha reduces laser-induced choroidal neovascularization. Exp Eye Res. 2006;83(6):1325-34

6. Dick AD, Forrest JV, Liversidge J, Cope AP. The role of tumor necrosis factor (TNF-alpha) in experimental autoimmune uveoretinitis (EAU). Prog Retin Eye Res. 2004;23(6):617-37.

7. Santos Lacomba M, Marcos Martin C, Gallardo Galera JM, Gómez Vidal MA, Collantes Estévez E, Ramírez Chamond R, et al. Aqueous humor and serum tumor necrosis factor alpha in clinical uveitis. Ophthalmic Res. 2001;33(5):251-5.

8. Okada AA, Sakai J, Usui M, Mizuguchi J. Intraocular cytokine quantification of experimental autoimmune uveoretinitis in rats. Ocul Imununol Inflamm. 1998;6(2):111-20.

9. Fleisher LN, Ferrell JB, McGahan MC. Ocular inflammatory effects of intravitreally injected tumor necrosis factor an endotoxin. Inflammation. 1990;14(3):325-35.

10. Rosenbaum JT Howes EL Jr, Rubin RM, Samples JR. Ocular inflammatory effects of intravitreally-injected tumor necrosis factor. Am J Pathol. 1988;133(1):47-53.

11. Santos Lacomba M, Marcos Martin C, Gallardo Calera JM, Gómez Vidal MA, Collantes Estévez E, Ramírez Chamond R, et al. Aqueous humor and serum tumor necrosis factor alpha in clinical uveitis. Ophthalmic Res. 2001:33(5):251-5.

12. Palexas GN, Sussman G, Welsh NH. Ocular and systemic determination of IL-1 beta and tumor necrosis factor in a patient with ocular inflammation. Scand J Immunol. 1192;1 1:173-5.

13. Dastgheib K, Green WR. Granulomatous reaction to Bruch's membrane in age - related macular degeneration. Arch Ophthalmol. 1994;112(6):813-8.

14. Hutchinson AK, Grossniklaus HE, Capone A. Giant-cell reaction in surgically excised subretinal neovascular membrane. Arch Ophthalmol. 1993:111(6):734-5.

15. Killingsworth MC, Sarks JP, Sarks SH. Macrophages related to Bruch's membrane in age related macular degeneration Eye (Lond). 1990;4(Pt 4):613-21.
16. Oh H, Takagi H, Takagi C, Suzuma K, Otani A, Ishida K, et al. The potential angiogenic role of macrophages in the formation of choroidal neovascular membranes. Invest Ophthalmol Vis Sci. 1999:40(9):1891-8.

17. Maini R, St Clair EW, Breedveld F, Furst D, Kalden J, Weisman M, et al. Infliximab (chimeric antitumor necrosis factor alpha monoclonal antibody) versus placebo in rheumatoid placebo en rheumatoid arthritis patients receiving concomitant methotrexate: a randomized phase III trial. ATTRATCT Study Group. Lancet. 2000;354(9194):1932-9.

18. Lewis JD. Anti-TNF antibodies for Crohn's disease-in pursuit of the perfect clinical trial. N Engl J Med. 2007;357(3):296-8.Comment in: N Engl J Med. 2007;357(16):1662; author reply 1662 Comment on: N Engl J Med. 2007;357(3):228-38. N Engl J Med. 2007;357(3):239-50.

19. Sfikakis PP, Kaklamanis PH, Elezoglou A,Katsilambros N, Theodossiadis PG, Papaefthimiou S, et al. Infliximab for recurrent sight-threatening ocular inflammation in AdamantiadesBehcet disease. Ann Intern Med. 2004;140(5):404-6.

20. Clegg DO. Treatment of ankylosing spondylitis. J Rheumatol. Suppl. 2006.78:24-31

21. Wong M, Ziring D, Desai S, Kim S, Lin J, et al. TN-alpha blockade in human diseases: mechanisms and future directions. Clin Imunol. 2008;126(2)121-36.

22. Sfikakis PP, Theodossiadis PG, Katsiari CG, Kaklamanis P, Markomichelakis NN. Effect of infliximab on sight-threatening panuveitis in Behcet's disease. Lancet. 2001;358(9278):295-6. Comment in:Lancet. 2001:358(9293):1644.

23. Marklomichelakis NN, Theodossiadis PG, Sfikakis PP. Regression of neovascular age-related macular degeneration following infliximab therapy. Am J Ophthalmol. 2005;139(3):537-40.

24. Sfikakis PP, Marklomichelakis N, Theodossiadis GP, Grigoropoulos V, Katsilambros N, Theodossiadis PG. Regression of sight-threatening macular edema in Type 2 diabetes following treatment with the anti-tumor necrosis factor monoclonal antibody infliximab. Diabetes Care. 2005;28(2):445-7.

25. Giansanti F, Ramazzotti M, Vannozzi L, Rapizzi E, Fiore T, laccheri B, et al. A pilot study on ocular safety of intravitreal infliximab in a rabbit model. Invest Ophthalmol Vis Sci. 2008;49(3): $1151-6$.

26. Theodossiadis PG, Liarakos VS, Sfikakis PP, Charosis A, Agrogiannis G, Kavantzas N, et al. Intravitreal administration of the anti-TNF monoclonal antibody infliximab in the rabbit. Graeffes Arch Clin Exp Ophthalmol. 2009; 247(2):273-81.

27. Hosseini H, Safael A, Khalili MR, Nowroozizadeh B, Eghtedari M, Farvardin M, et al. Intravitreal infliximab in experimental endotoxin-induced uveitis. Euro J Ophthalmol. 2009;19(5):818-23.

28. Theodossiadis PG, Liarakos VS, Sfikakis PP, Vergados IA, Theodossiadis GP. Intravitreal administration of the anti-tumor necrosis factor agent infliximab for neovascular agerelated macular degeneration. Am J Ophthalmol. 2009;147(5):825-30. Comment in: Am J Ophthalmol. 2009;147(5):761-3.

29. Giganti M, Beer PM, Lemanski N, Hartman C, Schartman J, Falk N. Adverse events following intravitreal infliximab (Remicade). Retina. 2010;30(1):71-80.

30. Farvadin M, Afarid M, Mehryar M, Hosseini H. Intravitreal infliximab for the reatment of sightthreatening chronic noninfectious uveitis. Retina. 2010;30(9):1530-5.

\title{
$37^{\circ}$ Congresso da Sociedade Brasileira de Retina e Vítreo
}

\author{
12 a 14 de abril de 2012 \\ Hotel Windsor \\ Barra da Tijuca - Rio de Janeiro - RJ
}

Informações:

Site: http://www.interevent.com.br/

E-mail: retina2012@interevent.com.br 